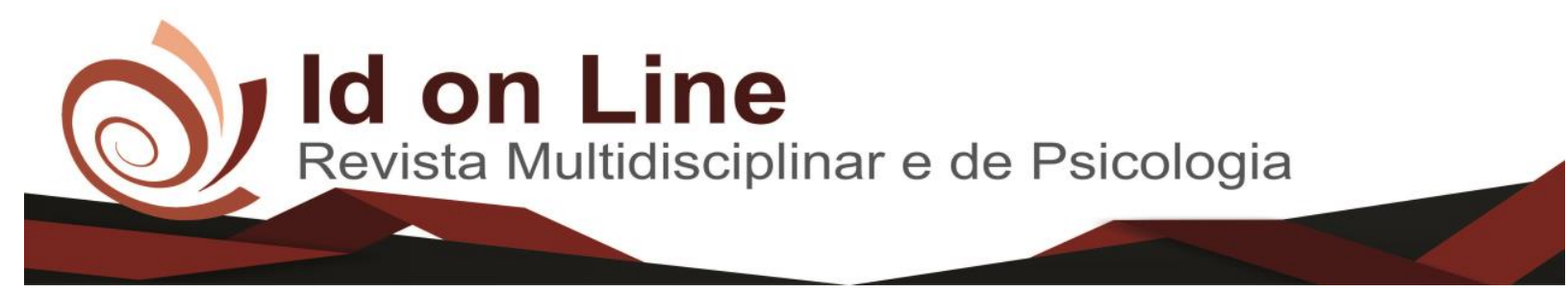

Artigo de Revisão

\title{
A Didática da Leitura nas primeiras séries do Ensino Fundamental I: Uma Reflexão Pedagógica
}

\author{
Maria das Dores de Matios $^{I}$; Penha Sebastião da Silva Rodrigues ${ }^{2}$
}

\begin{abstract}
Resumo: Sabe-se que muitas vezes o processo de leitura apresenta-se de forma fragmentada e descontextualizada da realidade social, sendo encarada, muitas vezes, como algo meramente artificial. Devido a isso, os professores encontram dificuldades em alcançar bons resultados nos seus trabalhos. Partindo então do pressuposto, o estímulo à leitura tem sido objeto de preocupação no âmbito escolar, pois na atualidade o maior desafio do professor é fazer com que a criança ou jovem realmente queira aprender. È inegável que o ato de ler é fundamental na formação do aluno e que considerável parcela ou toda a responsabilidade no desenvolvimento das habilidades de leitura recai sobre a escola. Nesse sentido, considera-se a leitura como algo essencial a qualquer ser humano, ainda mais percebendo sua importância no contexto atual, visto que, é através da mesma que tomamos conhecimentos dos nossos direitos e deveres enquanto cidadãos, para a existência e a possibilidade de uma vida humana participativa, na qual os indivíduos sejam capazes de expressar seus diversos pontos de vista, sua liberdade de usufruir de valores e bens de um determinado contexto partilhando deveres e poderes que pressupõe a existência de uma vida melhor em sociedade. É importante que se destaque a importância da interpretação de textos como agentes de transformação de jovens leitores e até mesmo da própria sociedade. Ler e compreender são uma forma de satisfazer muitas necessidades, ampliando e enriquecendo experiências através da riqueza de vocabulários da mudança de pontos de vista e da aquisição de novos valores. Este artigo objetiva investigar na literatura as práticas da leitura como fator social e transformador.
\end{abstract}

Palavras chave: Leitura. Cultura. Aprendizagem.

\section{The Didactics of Reading in the first years of Elementary School: A Pedagogical Reflection}

\begin{abstract}
It is known that the reading process is often fragmented and decontextualized from social reality, and is often seen as merely artificial. Because of this, teachers find it difficult to achieve good results in their work. Based on the assumption, the stimulus to reading has been an object of concern in the school environment, because at present the greatest challenge of the teacher is to make the child or youngster really want to learn. It is undeniable that the act of reading is fundamental in the formation of the student and that considerable portion or all responsibility in the development of the reading abilities falls on the school. In this sense, reading is considered essential to any human being, even more perceiving its importance in the current context, since it is through the same that we take knowledge of our rights and duties as citizens, for the existence and possibility of a participatory human life in which individuals are able to express their diverse points of view, their freedom to enjoy values and assets of a given context sharing duties and powers that presuppose the existence of a better life in society. It is important to emphasize the importance of interpreting texts as agents of transformation of young readers and even of society itself. Reading and understanding are a way of satisfying many needs, broadening and enriching experiences through the richness of vocabularies of changing points of view and the acquisition of new values. This article aims to investigate in the literature the practices of reading as a social and transforming factor.
\end{abstract}

Keywords: Reading. Culture. Learning.

\footnotetext{
${ }^{1}$ Graduada em Pedagogia pela Universidade Regional do Cariri. URCA. Pós-graduada em Geografia e meio pela Universidade Regional do Cariri, URCA. Pós-graduada em Gestão escolar pela Faculdade de Juazeiro do Norte-FJN. Mestranda em Ciências da Educação pela ANNE SULLIVAN- UNIVERSITY -Mestrado Internacional em Educação. Contato: mariadasdoresdematos@ gmail.com;

${ }^{2}$ Graduada em Língua Portuguesa e Literatura pela Universidade ESTADUAL Vale do Acaraú- UVA. Graduada em Pedagogia pela Faculdade Kurios FAK. Pós-Graduada em Língua Portuguesa e Literatura pela Universidade Estadual Vale do Acaraú- UVA. Mestranda em Ciências da Educação Pela ANNE SULIVAN. Contato: ppenhas@hotmail.com.
} 


\section{Introdução}

Com a invasão tecnológica e outros interesses poucas pessoas conservam o hábito de ler de forma convencional. Nesse sentido, a infância que é uma etapa primordial no processo de desenvolvimento da criança onde ela se desenvolve com mais facilidade pode ser prejudicada tendo em vista que falta estimulo inicialmente por parte da família.

Apesar dos inúmeros trabalhos acadêmicos produzidos referente à temática aqui abordada, ainda existe uma lacuna enorme entre informações pedagógicas de relevância e os professores de linguagem, sendo eles não os únicos, mas os primeiros responsáveis pela aplicabilidade de estratégias de leitura eficientes. Há com certeza muito a ser feito no intuito de melhor esclarecer a real situação em que se encontra o ensino da leitura atualmente.

Diante disso, esse artigo procura realizar um estudo sobre o ensino da leitura em uma das etapas da educação básica: ensino Fundamental I. Nesta análise reflexiva sobre as práticas e atividades de leitura que acontecem no $2^{\circ}$ ano do ensino fundamenta I.

Com esse artigo, pretende-se mostrar que durante muito tempo o ensino da leitura, no cenário educacional, se resumia ao ensino de letras, palavras e frases, dando pouquíssima importância à verdadeira intenção do ato de ler com significado, que é: compreensão e interação com o mundo, ou seja, não simplesmente saber ler, mas ser letrado.

Para a construção da pesquisa em tela foi preciso analisar algumas obras e trabalhos de referência significativa, em relação à temática abordada, e ao mesmo tempo pô-los em consonância com documentos que versam sobre as orientações do ensino da leitura como: Parâmetros Curriculares Nacionais PCNs, e Matrizes de Referências do Currículo Escolar que subsidiam e norteiam o ensino de leitura.

Objetiva-se, com este estudo, esclarecer dúvidas sobre a situação atual em que se encontra o ensino-aprendizagem da leitura nas séries iniciais da educação básica, e ao mesmo tempo mostrar a importância das orientações dadas pelos PCNs, que quando postas em prática, resultam em concretizações de projetos de sucesso e trazem contribuições valorosas para a nossa aprendizagem. Justifica-se a produção desta pesquisa, tendo em vista a grande necessidade que muitos professores do ensino fundamental I, ainda enfrentam em relação às orientações de práticas pedagógicas eficientes relacionadas ao ensino da leitura em sala de aula, pois a partir de um estudo pormenorizado, sobre o trabalho com a leitura.

283 Id on Line Rev. Mult. Psic. V.11, N. 39. 2017 - ISSN 1981-1179

Edição eletrônica em http://idonline.emnuvens.com.br/id 
Acredita-se que este estudo traz uma importância relevante por estar relacionado ao estudo da prática da leitura, sendo este um dos fatores indispensáveis em se tratando de aprendizagem.

Para tanto, esta pesquisa surgiu da necessidade em atender as exigências acadêmicas e da curiosidade sobre o tema, assim como a expectativa de evidenciar as práticas teóricas objetivando conhecer de que forma a contação de historias auxilia no desenvolvimento da criança respeitando seus tempos e direitos.

\section{Metodologia}

Os procedimentos metodológicos, desta pesquisa constituem-se em um estudo de caráter bibliográfico, onde a autora utiliza-se do diálogo entre autores relevantes a temática no sentido de entender e fazer-se entender de que forma a leitura pode ser considerada um recurso da aprendizagem e ao mesmo tempo possibilitar uma reflexão pedagógica.

Para realizarmos este projeto de pesquisa fizemos uso de literaturas divulgadas sobre o tema, analisando detalhes destas pesquisas, que confirmam o modo como se dá o processo de ensino da leitura nas séries inicias nos segundos anos do ensino fundamental.

Visando demonstrar com objetividade e credibilidade, a proposta deste artigo, dedicou-se ao estudo bibliográfico de algumas obras e autores que falam sobre a importância da leitura para a aprendizagem. Por se tratar-se de um estudo conceitual, com análises apenas em trabalhos já registrados, buscou-se identificar obras e autores que realmente demonstrassem segurança e autonomia sobre a temática.

Ao organizar essa pesquisa bibliográfica, tomando por base as informações relevantes sobre o tema e procurou-se citar os estudiosos que trabalharam a temática aqui abordada. Através de registros escritos e fichamentos das obras citadas, procurou-se elaborar um texto de linguagem simples e acessível. 


\section{Resultados e Discussão}

\section{O que é leitura?}

Leitura é a compreensão de textos e contextos que ampliam e enriquece experiências através da riqueza de vocabulários da mudança de pontos de vista e da aquisição de novos valores.

Ler é ampliar conhecimentos, interagindo em contato com a sociedade e o mundo, pois melhora a comunicação, a escrita e o relacionamento com os outros, levando o homem a interagir e a participar da vida social, política, econômica e cultural.

Um leitor competente tem uma prática constante de leitura, não ler apenas em sala de aula, apenas no livro didático, e sim porque desperta dentro de si o interesse em adquirir novos conhecimentos.

A leitura palta-se no ensino sua aprendizagem abordando a compreensão de textos escritos e não verbais em sua prática. Colomer (2003: 165) afirma que

$$
\begin{aligned}
& \text { (...) ler é um ato interpretativo que consiste em saber guiar uma série de raciocínios } \\
& \text { até a construção de uma interpretação da mensagem escrita, a partir tanto da } \\
& \text { informação que o texto proporciona como dos conhecimentos do leitor. }
\end{aligned}
$$

Portanto, ler de forma compreensiva é um processo complexo que envolve subjetividade percepção de fatores que derivam do leitor e também do texto. Neste caso, não é apenas um processo que envolve um emissor, uma mensagem codificada e o receptor que, por dominar o mesmo código do autor, decodifica a mensagem.

Solé apud Proposta Curricular (2004, p.27), nos ensina que a leitura é um processo de interação entre o leitor e o texto; neste processo tenta-se satisfazer (obter uma informação pertinente) os objetivos que guiam sua leitura.

A leitura é um dos meios mais importantes para a construção de novas aprendizagens, promove o fortalecimento de ideias e ações, permite ampliar conhecimentos e adquirir novos conhecimentos gerais e específicos, possibilitando a ascensão de quem lê a níveis mais elevados de desempenho cognitivo, como a aplicação de conhecimentos a novas situações, a análise e a crítica de textos e a síntese de estudos realizados. (GONÇALVES, 2013). 
Certamente com o mundo globalizado contemporâneo surgiu a necessidade de reorganização dos sistemas educacionais de todo o mundo e evidentemente com o Brasil não poderia ser diferente. As tecnologias no mundo do trabalho forçaram a busca imediata pela reconfiguração dos sistemas educacionais.

Segundo Nabeiro (2004, p. 13), uma sociedade que objetiva progredir através da modernização deve incluir no plano de desenvolvimento social e econômico a questão da cultura, pois esta trará suporte para o desenvolvimento global do indivíduo. Para que de fato exista esse crescimento cultural é importante que a sociedade como um todo repense a questão do livro e da leitura. Apesar de todo desenvolvimento tecnológico, o livro continua sendo, ainda, um grande meio de transmissão do conhecimento. É na leitura que encontramos a ferramenta fundamental para vivemos numa sociedade moderna e em constante evolução.

No ensino de leitura aos alunos do $2^{\circ}$ ano do ensino fundamental, o educador deve analisá-lo de modo a organizar e selecionar recursos ou estratégias de ensino que permitam aos discentes fazerem uma leitura do mundo e suas contradições, ampliar suas noções, construir e reconstruir conceitos e valorizar as diferentes ações sociais e culturais, levando-se em conta, seu perfil socioeconômico, cognitivo e afetivo. Vejamos o que ensina o educador Paulo Freire sobre leitura de mundo (1986, p.11).

(...) a retomada da infância distante, buscando a compreensão do meu ato de "ler" o mundo em que me movia até onde não sou traído pela memória me é absolutamente significativo. Neste esforço a que vou me entregando, recrio revivo, no texto que escrevo a experiência vivida no momento em que ainda não lia a palavra. (...) $\mathrm{Na}$ verdade, aquele mundo especial se dava a mim como o mundo de minhas primeiras leituras. Os 'textos', as 'palavras' e as 'letras' daquele contexto em cuja percepção me experimenta e, quanto mais o fazia, mais aumentava a capacidade de perceber se encarnavam numa série de coisas, de objetivos, de sinais, cuja compreensão eu ia aprendendo no meu trato com eles, nas minhas relações com meus irmãos mais velhos e meus pais.

A concepção do autor nos faz entender que o fato de vivermos em sociedade, de estarmos em constante interação com os outros a fim de compreendermos a nós mesmos e a tudo que está a nossa volta, faz parte de um longo processo de internalização de formas culturais. Ao mesmo tempo em que originam, também modificam nossos comportamentos, nossas concepções, nossa forma de tratar as pessoas, de emitir opiniões, enfim, de procurar decifrar, desvendar, explicar e dar sentido ao mundo. 


\section{O ensino de leitura}

Antes da criação da LDB vigente seguiam-se modelos de ensino da leitura muito suspeito no tocante a sua eficácia e resultados positivos. Dava-se importância a um ensino fragmentado e completamente descontextualizado, causando com isso total falta de interesse e de identificação do estudante com o ensino que era trabalhado ou pelo menos tentado, nas escolas. O ensino da língua materna reduzia-se ao ensino da gramática, não atribuindo importância alguma a outras habilidades inerentes à disciplina (GONÇALVES, 2013).

Com o advento da educação moderna, educação libertadora e redentora, parafraseando Paulo Freire (2001), divulgada por especialistas e revolucionários da educação, passou-se a ver com olhares mais críticos e verdadeiramente preocupados a questão da integralidade compreensiva dos textos e contextos, onde o aluno se enxergasse e deixasse de ser sujeito passivo e passasse a ser sujeito ativo, visto que tinha se tornado sujeito de direito.

Segundo Albuquerque (2008), se o ensino da leitura e da escrita sofre mudanças diversas e constantes ao longo da história, nas três ultimas décadas, vários foram os aspectos que influenciaram nestas mudanças. Foram transformadas bastantes as formas segundo as quais esse ensino tem sido concebido e posto em prática. Fatores como avanços teóricos na área, mudanças nas práticas sociais de comunicação e o pleno desenvolvimento das tecnologias forjaram novas propostas pedagógicas e a produção de novas matérias didáticas, relacionada à alfabetização inicial e ao ensino de línguas em geral.

Nos últimos anos, finalmente podemos verificar que os esforços empreendidos para uma modificação na educação brasileira vêm surtindo efeitos positivos. Logicamente resultados bem tímidos quase imperceptíveis, porém avanços que certamente motivam os profissionais que buscam e aplaudem esses resultados. Certamente ainda existe muita coisa a ser feita, porém acreditamos que ao longo dos anos com os esforços que vem sendo empreendidos teremos uma postura positiva e relevante em relação ao ensino da leitura no cenário educacional brasileiro.

A leitura tem um papel fundamental no processo de cidadania. Pois prepara o indivíduo a repensar sobre a realidade, na qual está inserido, a maneira de relacionamento impregnada de injustiça, desigualdade, preconceito, etc. assim podemos observar que a leitura deve propiciar aquisição de conhecimentos, o desenvolvimento das habilidades e valores 
necessários para que o indivíduo melhore a qualidade de vida, participe ativamente e efetivamente da sociedade onde está envolvido.

Diante do exposto, pode-se afirmar que a leitura é um meio pelo qual o homem encontra a liberdade, pois a partir do conhecimento adquirido através da leitura ele terá melhores condições de discutir e propor ideias ou discordar delas com mais segurança e liberdade.

Nesse contexto, os PCN's (Parâmetros Curriculares Nacionais) 1997 tratam a leitura como um dos principais objetivos de ensino na escola, podendo constatar que a mesma tem como finalidade a de formar leitores competentes, e consequentemente a formação e realização de um processo no qual o leitor possa realizar fazendo um trabalho vivo para melhor produção e construção de um texto.

Assim, compreende-se que o domínio da leitura e escrita é fundamental para a participação social e efetiva, pois é por meio dela comunica-se, tem-se acesso a informação, se expressa e defende-se pontos de vista, compartilha ou constrói visões de mundo e, produz conhecimentos.

\section{Modalidades de leitura}

As práticas de leitura na atualidade são de extrema importância, pois possibilita desenvolvimento de aprendizagem. O aluno aprende a ler lendo, e essa tarefa não limita-se apenas na disciplina de língua portuguesa, mas nas demais. Para ter significado mais amplo veremos a seguir as diferentes práticas de leitura segundo (COLOMER 2003):

- Leitura de audição: você ler os outros escuta. Acontece quando o professor quer chamara atenção dos alunos em sala de aula, por exemplo, o ideal é que seja tirado o material do aluno para que este realmente preste atenção, esta é a leitura em voz alta apresentada como impacto, ou seja, ela é enfática,

- Leitura colaborativa: Esta por sua vez apresenta-se em grupo ou ensaiada, geralmente o professor pede para o aluno fazer de modo que a torne marcante;

- Leitura orientada: esta faz com que o aluno faça uma leitura mais concentrada de modo que não perca alinha de raciocínio, é muito comum em grupos de estudo; 
- Leitura individual: essa é feita com que seja trabalhada a leitura de aluno por aluno;

- Leitura comentada: é a que procura transbordar as informações externas ao texto, ou seja, a interdisciplinaridade age de forma muito frequente, leitura especifica dividida em etapas e eventos;

- Leitura episódica: essa consiste em ser dividida em etapas e eventos.

Essas práticas de leitura são muito importantes, o ideal é que o professor em sala de aula as utilize de forma a alcançar o objetivo que cada uma requer. As estratégias e práticas de leituras estão relacionadas a várias outras habilidades. A leitura por sua vez, é uma interação entre o leitor e o texto. (SOLÉ, 2008). Essa afirmativa pode-se estender bastante pelo fato de existir vários tipos de informação, ou seja, vários tipos de cultura, Essa relação pode ser mediada por um livro, jornal e outros, sendo esses os objetos que vão trazer as informações.

A leitura nesse sentido, pode se dar por vários motivos, podem ser eles: por lazer, para se obter uma informação, por devaneio, por necessidade objetiva coletiva ou subjetiva individual, pesquisa. Na sala de aula é interessante que o professor mostre ao aluno que há vários motivos para praticar as mais variadas formas de leituras, não só na hora da prova, independente de qual seja a finalidade o aluno precisa saber desde cedo que a leitura pode atender as diversas necessidades e finalidades inclusive práticas.

Também como ocorre com as dificuldades de aprendizagem, definidas genericamente, é uma tarefa igualmente difícil especificar fatores ou indicadores definitivos que estejam realmente implicados na origem das dificuldades de leitura. Também se constata na literatura especializada uma gama de fatores que podem contribuir para que essa dificuldade se instale. Diante desse contexto, a escrita pode ser estudada com base em diferentes perspectivas e modelos teóricos (Guimarães, 2001).

Assim, a compreensão do texto exige que se tenha habilidade de leitura de modo que as informações que se inserem no texto sejam entendidas e interpretadas, gerar hipóteses, fazer previsões depois conferir. 


\section{Considerações Finais}

Os estudos atuais enfatizam a importância da construção e utilização de materiais adequados á realidade vivenciada pelas crianças com problemas de aprendizagem relacionados à leitura, com um bom profissional se constitui o marco referencial para enfrentar as dificuldades cotidianas e reencaminhar novos rumos. Nesse sentido, o compromisso da escola torna-se maior em identificar e propor alternativas didáticas viáveis para que os alunos possam superar eventuais dificuldades que apresentam.

Esta pesquisa sobre a importância da leitura nas series iniciais teve como objetivo deixar claro que a criança se desenvolve integralmente quando passa a conhecer outros horizontes. Dessa forma, percebe-se que um ambiente organizado e aconselhador facilita o desempenho da aprendizagem das crianças.

A partir das analises bibliográficas realizadas referentes ao tema, conclui-se que as práticas de leitura fortalece o trabalho do educador e permite aos alunos um desenvolvimento mais completo, pois na maioria das vezes e apenas na escola que elas têm contato com histórias que lhes ajuda a perceber a ludicidade das palavras, podendo criar e recriar.

Após deixar clara a importância da leitura não só no contexto escolar, ressalta-se seu valor para a formação integral do aluno da educação desde o infantil, tanto na educação escolar quanto na educação social.

Essa pesquisa não se esgota por aqui, pois sobre essa temática ainda há muito que se pesquisar por perceber que a rotina da contação de histórias em sala de aula é tratada como um precioso recurso metodológico pedagógico, tornando assim, a aprendizagem leitora rica e cheia de significados desde a infância, isso sem dúvidas possibilitará ao individuo a inserção na sociedade como sujeito participante ativo de forma reflexiva.

\section{Referências}

ALBUQUERQUE, E. B. C. Mudanças didáticas e pedagógicas do ensino da língua portuguesa: apropriações de professores. Belo Horizonte: Autêntica, 2008. 
E. B. C; MORAIS, A. G; FERREIRA, A. T. B. As práticas cotidianas de alfabetização: $O$ que fazem os professores? Revista Brasileira de Educação, v.13, p. 252264, 2008.

BATISTA, A. A G. Aula de português: discurso e saberes escolares. São Paulo: Martins Fontes, 1997.

BRASIL, Ministério da Educação. Guia de livros didáticos PNLD 2008: apresentação / Ministério da Educação. - Brasília: MEC, 2007.

BRASIL. ECA - Estatuto da criança e do Adolescente. Lei federal $n^{\circ} 8.069$, de 13 de junho de 1990. Disponível em :http://www.dominiopublico.gov.br/dawload/sf0009a.pdf.acesso em: 30 de novembro . 2017

BRASIL. LDB - Leis de Diretrizes e Bases da Educação Nacional. Lei Federal n ${ }^{\text {o }}$ 9.394/96, de 20 de dezembro de 1996. Disponível em:

http://portal.mec.gov.br/arquivo/pdf/ldb.pdf.acesso em: 28 novembro. 2017.

BRASIL. Ministério da Educação e Cultura. Parâmetros Curriculares Nacionais - Brasília, 2007.

COLOMER, T. O ensino e a aprendizagem da compreensão em leitura. In: LOMAS, Carlos. (org.) $\mathbf{O}$ valor das palavras: falar, ler e escrever nas aulas. $1^{\mathrm{a}} \mathrm{Ed}$. Lisboa -2003.

FREIRE, P. A importância do ato de ler: em três artigos que se completam. 26 ed. São Paulo: Cortez, 1991.

À sombra desta mangueira. 2. ed. São Paulo: Olho d'Água, 1995. 120 p.

Educação como prática da liberdade. 25. ed. São Paulo: Paz e Terra, 2001.

$158 \mathrm{p}$.

Pedagogia da autonomia: saberes necessários à prática educativa. 30. ed. Rio de Janeiro: Paz e Terra, 2004. 148 p. (Coleção leitura).

SOARES, M. Letramento e escolarização. In: RIBEIRO, Vera Masagão. Letramento no Brasil. São Paulo: Global, 2004. P. 27.

\section{Como citar este artigo (Formato ABNT):}

MATOS. Maria das Dores de.; RODRIGUES. Penha Sebastião da Silva. A Didática da Leitura nas primeiras séries do Ensino Fundamental I: Uma Reflexão Pedagógica. Id on Line Revista ultidisciplinar e de Psicologia, 2017, vol.12, n.39, p.282-291. ISSN: 1981-1179. 